\title{
Potential solutions to face abcd and diabetes in mexico and worldwide
}

\section{Opinion}

Currently, the huge public health problem that we face in Mexico $^{1-4}$ and worldwide ${ }^{5-7}$ can be counteracted by acting on 4 levels, as has been proposed by the ecological model: Individual, Family, Society and Health Policies. ${ }^{8}$ According to our experience with more than 400 families and 800 people (adults and children) inside our "Sacbe" program (comprehensive clinical and nutritional familybased program), ${ }^{9,10}$ there are 3 strong and potential solutions: 1 . Give massive education in each society, 2. Limit or suspend the production of junk food, 3. Give better salaries in Mexico and worldwide. Education must focus about a healthy lifestyle in order to prevent and treat diabetes, ${ }^{11,12}$ understanding why our current habits of lifestyle are harming our health status, why obesity and overweight must be considered as a serious chronic disease like diabetes that need to be taken care of by a health team, and give strategies according to each family and individual context to achieve changes. ${ }^{13}$ It is worrisome that parents are not aware of their actual weight status or that of their children and, when there is awareness of excess weight, they do not understand it as a chronic disease, even they consider overweight and obesity like something aesthetic or only a risk factor, in fact, in several cases parents think that overweight is good for the health or transitory because children are growing and will become normal in the adulthood..$^{14,15}$

For this reason, it is an excellent proposal to change the term overweight and obesity by ABCD (Adiposity-Based Chronic Disease), such as last year was suggested. ${ }^{16}$ Why are the programs to treat obesity and diabetes successful between 20 and $30 \%$ ? because the rest of the percentage of success depends on changes in the family, in the whole society and in health policies. ${ }^{6}$ Therefore, if we really want to face the pandemic of these chronic diseases, we must face it in an integral and not isolated way. The knowledge is power and the best way to change the world. "Sacbe", our comprehensive program has reached success in $50-80 \%$ of children and their parents in the first month, 3 and 6 months of follow-up because we try and educate whole families but considering their socio-cultural context. "Sacbe" participants achieve these goals: Understanding of obesity and overweight as $\mathrm{ABCD}$, being aware of their real weight status and consequences and the role of unhealthy habits to origin $\mathrm{ABCD}$ and Diabetes. Thus, they decide to decrease or suspend junk food intake and improve other unhealthy habits (sedentary lifestyle, short sleep duration, skip meals, zero or insufficient consumption of vegetables and fruits, poor water intake, stress, bad attitude). Through education, they decide to change by conviction and not by imposition; family communication improve and 2 or more family members join efforts to improve their lifestyle ${ }^{9,10}$ in spite of limited time and poor incomes. ${ }^{17-19}$

The multiple economic, family and personal problems far exceed the desire of people and whole families to take care of their health but undoubtedly, the education of Sacbe program could be a model to educate the whole society in Mexico and in each country with adaptations according sociocultural contexts. It is basic understanding the serious damage caused to health and the environment by the
Volume 2 Issue I - 2018

\author{
Ana Rodriguez-Ventura \\ Department of Research in Nutrition and Bioprogramming, \\ National Institute of Perinatology, Mexico
}

Correspondence: Ana Rodriguez Ventura, Department of Research in Nutrition and Bioprogramming, National Institute of Perinatology, Mexico, Email rovalilia@hotmail.com

Received: February 13, 2018 | Published: February 21, 2018

excessive consumption of junk food and it will make easier for health policies to limit the production of this or improve its quality. Health policies should favor the creation ${ }^{20}$ of interdisciplinary health teams (doctor, registered dietitian, psychologist and physical activator) trained to treat $\mathrm{ABCD}$ and diabetes in schools and workplaces. On the other hand, health policies should ensure that workplaces are close to workers' houses, that workday time duration is reasonable to allow leisure time activities and that the salaries cover the basic needs of each family so that they have enough time and tranquility to reach and maintain healthy habits. Currently in Mexico, an economic study of the Universidad Nacional Autónoma de México, ${ }^{21}$ has calculated that people need to work more than 24 hours per day in order to buy basic food and services to live. There is a huge disproportion between salaries and what is required to cover the basic needs of a person.

Besides, we need to consider that there are other important factors that contribute to this pandemic, such as obesity pre-pregnancy, excessive gestational weight-gain, gestational diabetes, absence of breastfeeding, overfeeding of children in the first months and/or poor quality of food. These conditions are programming new generations to develop chronic diseases soon, at younger ages, even from childhood $^{22}$ and with outcomes worst than same chronic disease in adults, for example, the TODAY study, the biggest multicenter study in adolescents and young with type 2 diabetes, has reported that $50 \%$ of children participants require insulin after 2 years of evolution ${ }^{23}$ and $20 \%$ of newborn's of young woman participants presented congenital malformations. ${ }^{24}$ Experts have alerted that it is possible that life expectancy in children will be shorter than their parents. ${ }^{25} \mathrm{~A}$ truly civilized society should direct all its resources to develop happy children and healthy adults who are aging in dignified conditions, not only because of a high sense of humanity, but also because of the high economic cost could be saved through the prevention and good control of $\mathrm{ABCD}$ and diabetes.

\section{Acknowledgements}

None.

\section{Conflict of interest}

The author declares no conflict of interest. 


\section{References}

1. Shamah Levy T, Cuevas Nasu L, Rivera Dommarco J. Encuesta Nacional de Salud y Nutrición de Medio Camino 2016. Instituto Nacional de Salud Pública, México; 2016. p. 147-169.

2. Bello Chavolla OY, Rojas Martinez R, Aguilar Salinas CA, et al Epidemiology of diabetes mellitus in Mexico. Nutr Rev. 2017;75(Suppl $1): 4-12$.

3. Alegre Díaz J, Herrington W, López Cervantes M, et al. Diabetes and cause-specific mortality in Mexico City. $N$ Engl $J$ Med. 2016;375(20):1961-1971.

4. Afshin A, Forouzanfar MH, Reitsma MB, et al. Health Effects of Overweight and Obesity in 195 Countries over 25 Years. New Engl $J$ Med. 2017;77(1):13-27.

5. Dabelea D, Mayer Davis EJ, Saydah S, et al. Prevalence of Type 1 and Type 2 Diabetes Among Children and Adolescents From 2001 to 2009. JAMA. 2014;311(17):1778-1786.

6. Mayer Davis EJ, Lawrence JM, Dabelea D, et al. Incidence trends of type 1 and type 2 diabetes among youths, 2002-2012. N Engl J Med. 2017;376(15):1419-1429.

7. Dabelea D, Stafford JM, Mayer Davis EJ. Association of type 1 diabetes vs. type 2 diabetes diagnosed during childhood and adolescence with complications during teenage years and young adulthood. JAMA. 2017;317(8):825-835.

8. González Castro F, Shaibi G, Boehm Smith E. Ecodevelopmental contexts for preventing type 2 diabetes in Latino and other racial/ethnic minority populations. J Behav Med. 2009;32(1):89-105.

9. Rodríguez Ventura AL. Eficacia de "Sacbe" para disminuir índice de masa corporal en niños con sobrepeso/obesidad y otros factores de riesgo para desarrollar diabetes tipo 2 [tesis de doctorado]. Ciudad de México (CDMX): Universidad Nacional Autónoma de México; 2015. 60 p.

10. Parra Solano A. Cambios en hábitos alimentarios de niños y adolescentes con obesidad y sobrepeso con disminución del índice de masa corpora [tesis de maestría]. Cd. De México: Universidad Nacional Autonóma de México; 2017.54 p.

11. Knowler WC, Barrett Connor E, Fowler SE. Diabetes Prevention Program Research Group. Reduction in the incidence of type 2 diabetes with lifestyle intervention or metformin. N Engl J Med. 2002;346(6):393-403.

12. Grey M, Schreiner B, Pyle L. Treatment Options for Type 2 Diabetes in Adolescents and Youth (TODAY) Study Group. Development of a Diabetes Education Program for Youth with Type 2 Diabetes. Diabetes Education. 2009;35:108-116.

13. Huang TT K, Goran MI. Prevention of type 2 diabetes in young people: a theoretical perspective. Pediatric Diabetes. 2003;4(1):38-56.
14. Rodríguez Ventura AL, Pelaez Ballestas I, Sámano R, et al. Barriers to Lose Weight from the Perspective of Children with Overweight/Obesity and Their Parents: A Sociocultural Approach. J Obes. 2014;2014 (2014):7 p.

15. Sámano R, Rodríguez Ventura A. Satisfacción de la imagen corporal en adolescentes y adultos mexicanos y su relación con la autopercepción corporal y el índice de masa corporal real. Nutrición Hospitalaria. 2015;31(3):1082-1088.

16. Mechanik J, Hurley D, Garvey WT. Adiposity-based chronic disease as a new diagnostic term: American Association of Clinical Endocrinologists and the American College of Endocrinology Position Statement. Endocrine Practice. 2016;23(3):372-378.

17. Oude Luttikhuis $\mathrm{H}$, Baur L, Jansen $\mathrm{H}$, et al. Interventions for treating obesity in children (Review). Cochrane Database Syst Rev. 2009;21(1):CD001872.

18. German JN, Kirschenbaum DE, Rich BH, et al. Long-term evaluation of multi-disciplinary treatment of morbid obesity in low-income minority adolescents: La Rabida Children': Hospital's Fit Matters Program. J Adolesc Health. 2006;39:553-561.

19. Saydah SH, Fradkin J, Cowie CC. Poor control of risk factors for vascular disease among adults with previously diagnosed diabetes. JAMA. 2004;291(3):335-342.

20. Gerstl EM, Rabl W, Rosenbauer J, et al. Metabolic control as reflectet by $\mathrm{HbA} 1 \mathrm{c}$ in children, adolescents and young adults with type-1 diabetes mellitus: combined longitudinal analysis including 27035 patients from 207 centers in Germany and Austria during the last decade. Eur J Pediatr. 2008; $167: 447-453$

21. Centro de Análisis Multidisciplinario de la UNAM. con datos de la Conasami y del cuestionario sobre precios básicos, Mexico; 2018. p. 4-25.

22. Daniels SR. The consequences of childhood overweight and obesity. Future Child. 2006;16(1):47-67.

23. Phil Zeitler, Kathryn Hirst, Kenneth C, et al. HbA1c After a Short Period of Monotherapy With Metformin Identifies Durable Glycemic Control Among Adolescents With Type 2 Diabetes. Diabetes Care. 2015;38:2285-2292.

24. Chernausek SD, Arslanian S, Caprio S, et al. Relationship between parental diabetes and presentation of metabolic and glycemic function in youth with type 2 diabetes: Baseline findings from the TODAY trial. Diab Care. 2016;39(1):110-117.

25. Zambrano E, Ibáñez C, Martínez Samayoa PM, et al. Maternal Obesity: Lifelong Metabolic Outcomes for Offspring from Poor Developmental Trajectories During the Perinatal Period. Archives of Medical Research. $2016 ; 47(1): 1-12$ 